\title{
Study of whole genome linkage disequilibrium in Nellore cattle
}

\author{
Rafael Espigolan', Fernando Baldi ${ }^{1,3}$, Arione A Boligon ${ }^{1}$, Fabio RP Souza', Daniel GM Gordo ${ }^{1}$, Rafael L Tonussi ${ }^{1}$, \\ Diércles F Cardoso ${ }^{1}$, Henrique N Oliveira ${ }^{1,2,5}$, Humberto Tonhati ${ }^{1,2,5}$, Mehdi Sargolzaei ${ }^{4}$, Flavio S Schenkel ${ }^{4}$, \\ Roberto Carvalheiro ${ }^{6}$, Jesus A Ferro ${ }^{1}$ and Lucia G Albuquerque ${ }^{1,2,5^{*}}$
}

\begin{abstract}
Background: Knowledge of the linkage disequilibrium (LD) between markers is important to establish the number of markers necessary for association studies and genomic selection. The objective of this study was to evaluate the extent of LD in Nellore cattle using a high density SNP panel and 795 genotyped steers.

Results: After data editing, 446,986 SNPs were used for the estimation of LD, comprising $2508.4 \mathrm{Mb}$ of the genome. The mean distance between adjacent markers was $4.90 \pm 2.89 \mathrm{~kb}$. The minor allele frequency (MAF) was less than 0.20 in a considerable proportion of SNPs. The overall mean LD between marker pairs measured by $r^{2}$ and $\left|D^{\prime}\right|$ was 0.17 and 0.52 , respectively. The LD $\left(r^{2}\right)$ decreased with increasing physical distance between markers from $0.34(1 \mathrm{~kb})$ to 0.11 (100 kb). In contrast to this clear decrease of LD measured by $r^{2}$, the changes in $\left|D^{\prime}\right|$ indicated a less pronounced decline of LD. Chromosomes BTA1, BTA27, BTA28 and BTA29 showed lower levels of LD at any distance between markers. Except for these four chromosomes, the level of $L D\left(r^{2}\right)$ was higher than 0.20 for markers separated by less than $20 \mathrm{~kb}$. At distances $<3 \mathrm{~kb}$, the level of LD was higher than 0.30. The LD $\left(\mathrm{r}^{2}\right)$ between markers was higher when the MAF threshold was high (0.15), especially when the distance between markers was short.
\end{abstract}

Conclusions: The level of LD estimated for markers separated by less than $30 \mathrm{~kb}$ indicates that the High Density Bovine SNP BeadChip will likely be a suitable tool for prediction of genomic breeding values in Nellore cattle.

Keywords: Beef cattle, Genome, Linkage disequilibrium, Genome, Molecular markers

\section{Background}

Nellore is a beef cattle (Zebu) breed that originated in India. The first specimens of the breed arrived in Brazil at the end of the 18th century and Nellore animals rapidly became the predominant breed in the Brazilian herd [1]. There are about 200 million cattle heads in Brazil and most of them (about $80 \%$ ) are Zebu animals and their crossbreds [2]. Over the past decades, there has been an increased interest to use genetically evaluated animals in the Zebu population. As a consequence, several genetic evaluation programs of Zebu breeds exist, particularly for Nellore cattle. The main focus of these programs is growth and conformation traits, which are used as selection criteria [3].

\footnotetext{
* Correspondence: Igalb@fcav.unesp.br

${ }^{1}$ Faculdade de Ciências Agrárias e Veterinárias, UNESP, Jaboticabal, SP 14884-000, Brazil

${ }^{2}$ Instituto Nacional de Ciência e Tecnologia - Ciência Animal (INCT- CA), Viçosa, MG 36570 000, Brazil

Full list of author information is available at the end of the article
}

The breeding value of animals can be obtained from genomic data by marker-assisted selection covering the whole genome, also called genomic selection [4,5]. Genomic selection explores the linkage disequilibrium (LD) between markers, assuming that the effects of chromosome segments will be the same in the whole population since the markers are in LD with genes that are responsible for expression of the trait (quantitative trait loci, QTL). Therefore, the density of markers should be sufficiently high to guarantee that all QTL are in LD with a marker or with a marker haplotype. The LD maps are important tools for exploring the genetic basis of economically important traits in cattle. Likewise, comparison of LD maps permits to establish the diversity between cattle breeds with different biological attributes and to identify genome regions that were subject to different selection pressures [6].

The two measures most commonly used to evaluate LD between biallelic markers are $r^{2}$ and $\left|D^{\prime}\right|$ [7-10]. These

\section{Biomed Central}


parameters can vary between 0 and 1 . A value of $\left|D^{\prime}\right|<1$ indicates the occurrence of recombination between two loci, and $\left|\mathrm{D}^{\prime}\right|=1$ indicates the lack of recombination between two loci. One disadvantage of $\left|D^{\prime}\right|$ is that it tends to be strongly overestimated in small samples and in the presence of rare or low-frequency alleles. The $\mathrm{r}^{2}$ parameter represents the correlation between two loci and is preferred in association studies since an inverse relationship exists between $r^{2}$ and the size of the sample needed for the same detection power. Linkage disequilibrium is necessary to detect associations between a QTL and a marker [11].

The LD between markers has been studied in the genome of taurine breeds. In this respect, [12] analyzing 505 SNPs located on chromosome 14 of Holstein cattle, reported moderate levels of $\operatorname{LD}\left(r^{2}=0.2\right)$ for markers separated by less than $100 \mathrm{~kb}$. Similar results have been reported by [6] who estimated the $\operatorname{LD}\left(r^{2}\right)$ between 2,670 markers in eight cattle breeds. Villa-Angulo et al., 2009 [13] studied the genomes of 19 taurine and Zebu breeds using a set of 32,826 SNPs. The authors observed that Zebu breeds have a higher proportion of low-frequency alleles and a lower level of LD than taurine breeds. Recently, [14] genotyped 25 Gyr bulls using a panel of 54,000 markers (SNPs) and obtained a mean LD $\left(r^{2}\right)$ between adjacent markers of 0.21 .

The first step necessary to determine the number of markers required for QTL mapping and genomic selection is the quantification of the extent of LD in the cattle genome. Therefore, the objective of the present study was to evaluate LD in Nellore cattle using a high density SNP panel (Illumina High Density Bovine SNP BeadChip ${ }^{\circledR}$ ).

Table 1 Summary of the SNP markers analyzed and average linkage disequilibrium ( $r^{2}$ and |D'|) between synthetic adjacent markers obtained for each autosome (BTA) ${ }^{1}$

\begin{tabular}{|c|c|c|c|c|c|c|c|c|}
\hline BTA & Size $(\mathrm{Mb})$ & SNP (n) & Mean distance \pm SD $(\mathrm{kb})$ & Mean $r^{2} \pm S D$ & Median $r^{2}$ & Mean $\left|D^{\prime}\right| \pm S D$ & Median |D'| & Mean MAF \pm SD \\
\hline 1 & 158.5 & 28,569 & $5.0 \pm 2.9$ & $0.12 \pm 0.22$ & 0.015 & $0.38 \pm 0.34$ & 0.26 & $0.25 \pm 0.13$ \\
\hline 2 & 136.8 & 23,866 & $5.1 \pm 2.9$ & $0.19 \pm 0.25$ & 0.077 & $0.57 \pm 0.32$ & 0.60 & $0.25 \pm 0.13$ \\
\hline 3 & 121.4 & 22,592 & $5.1 \pm 2.9$ & $0.19 \pm 0.25$ & 0.081 & $0.57 \pm 0.32$ & 0.60 & $0.25 \pm 0.13$ \\
\hline 4 & 120.6 & 20,907 & $5.1 \pm 2.9$ & $0.18 \pm 0.24$ & 0.071 & $0.56 \pm 0.32$ & 0.59 & $0.25 \pm 0.13$ \\
\hline 5 & 121.1 & 20,092 & $5.1 \pm 2.9$ & $0.20 \pm 0.25$ & 0.086 & $0.58 \pm 0.32$ & 0.62 & $0.26 \pm 0.13$ \\
\hline 6 & 119.4 & 23,500 & $5.1 \pm 2.9$ & $0.19 \pm 0.25$ & 0086 & $0.57 \pm 0.32$ & 0.62 & $0.27 \pm 0.13$ \\
\hline 7 & 112.6 & 20,181 & $5.1 \pm 2.9$ & $0.20 \pm 0.25$ & 0.082 & $0.56 \pm 0.32$ & 0.60 & $0.25 \pm 0.13$ \\
\hline 8 & 113.3 & 21,667 & $5.2 \pm 2.8$ & $0.20 \pm 0.25$ & 0.097 & $0.59 \pm 0.32$ & 0.64 & $0.26 \pm 0.13$ \\
\hline 9 & 105.6 & 20,593 & $5.1 \pm 2.9$ & $0.19 \pm 0.25$ & 0.078 & $0.56 \pm 0.32$ & 0.59 & $0.26 \pm 0.13$ \\
\hline 10 & 104.2 & 17,213 & $5.0 \pm 2.9$ & $0.18 \pm 0.25$ & 0.064 & $0.57 \pm 0.32$ & 0.55 & $0.25 \pm 0.13$ \\
\hline 11 & 107.2 & 18,477 & $5.0 \pm 2.9$ & $0.19 \pm 0.25$ & 0.070 & $0.56 \pm 0.32$ & 0.59 & $0.24 \pm 0.13$ \\
\hline 12 & 91.1 & 15,556 & $5.1 \pm 2.9$ & $0.18 \pm 0.24$ & 0.070 & $0.55 \pm 0.32$ & 0.57 & $0.24 \pm 0.13$ \\
\hline 13 & 84.2 & 14,145 & $5.1 \pm 2.9$ & $0.21 \pm 0.26$ & 0.094 & $0.59 \pm 0.32$ & 0.65 & $0.25 \pm 0.13$ \\
\hline 14 & 83.9 & 16,909 & $5.2 \pm 2.8$ & $0.18 \pm 0.24$ & 0.079 & $0.56 \pm 0.32$ & 0.59 & $0.26 \pm 0.13$ \\
\hline 15 & 85.2 & 14,669 & $5.0 \pm 2.9$ & $0.18 \pm 0.24$ & 0.067 & $0.54 \pm 0.32$ & 0.56 & $0.24 \pm 0.13$ \\
\hline 16 & 81.7 & 14,715 & $5.0 \pm 2.9$ & $0.18 \pm 0.24$ & 0.072 & $0.56 \pm 0.32$ & 0.59 & $0.25 \pm 0.13$ \\
\hline 17 & 75.1 & 14,108 & $5.1 \pm 2.9$ & $0.19 \pm 0.26$ & 0.068 & $0.55 \pm 0.32$ & 0.58 & $0.24 \pm 0.13$ \\
\hline 18 & 65.9 & 11,461 & $5.0 \pm 2.9$ & $0.15 \pm 0.22$ & 0.051 & $0.52 \pm 0.31$ & 0.52 & $0.24 \pm 0.13$ \\
\hline 19 & 63.9 & 9,889 & $5.0 \pm 2.9$ & $0.20 \pm 0.26$ & 0.088 & $0.59 \pm 0.32$ & 0.63 & $0.24 \pm 0.13$ \\
\hline 20 & 71.9 & 12,734 & $5.0 \pm 2.9$ & $0.18 \pm 0.24$ & 0.067 & $0.54 \pm 0.32$ & 0.55 & $0.25 \pm 0.13$ \\
\hline 21 & 71.6 & 12,882 & $5.1 \pm 2.9$ & $0.17 \pm 0.24$ & 0.064 & $0.55 \pm 0.32$ & 0.57 & $0.24 \pm 0.13$ \\
\hline 22 & 61.3 & 10,442 & $5.0 \pm 2.9$ & $0.16 \pm 0.23$ & 0.061 & $0.54 \pm 0.32$ & 0.55 & $0.25 \pm 0.13$ \\
\hline 23 & 52.5 & 9,369 & $5.1 \pm 2.9$ & $0.17 \pm 0.24$ & 0.063 & $0.55 \pm 0.32$ & 0.58 & $0.25 \pm 0.13$ \\
\hline 24 & 62.3 & 11,300 & $5.1 \pm 2.9$ & $0.17 \pm 0.23$ & 0.063 & $0.54 \pm 0.32$ & 0.56 & $0.25 \pm 0.13$ \\
\hline 25 & 42.8 & 7,537 & $5.1 \pm 2.9$ & $0.16 \pm 0.22$ & 0.058 & $0.55 \pm 0.32$ & 0.56 & $0.23 \pm 0.13$ \\
\hline 26 & 51.6 & 9,503 & $5.0 \pm 2.9$ & $0.17 \pm 0.23$ & 0.062 & $0.54 \pm 0.31$ & 0.56 & $0.24 \pm 0.13$ \\
\hline 27 & 45.4 & 7,963 & $5.0 \pm 2.9$ & $0.09 \pm 0.18$ & 0.020 & $0.42 \pm 0.31$ & 0.36 & $0.25 \pm 0.13$ \\
\hline 28 & 46.2 & 7,858 & $4.9 \pm 2.9$ & $0.02 \pm 0.07$ & 0.003 & $0.25 \pm 0.25$ & 0.16 & $0.25 \pm 0.13$ \\
\hline 29 & 51.1 & 8,289 & $4.9 \pm 2.9$ & $0.003 \pm 0.01$ & 0.001 & $0.12 \pm 0.14$ & 0.07 & $0.24 \pm 0.13$ \\
\hline
\end{tabular}

SNP: single-nucleotide polymorphism; MAF: minor allele frequency; SD: Standard deviation. ${ }^{1}$ Data in the table is based on the UMD 3.1 assembly. 


\section{Results and discussion}

The results of descriptive statistics of the SNP markers and LD $\left(\mathrm{r}^{2}\right.$ and $\left.\left|\mathrm{D}^{\prime}\right|\right)$ between synthetic adjacent markers obtained for each autosome are shown in Table 1. A total of 446,986 (57.5\%) markers met the filtering criteria and were included in the final analysis. This sub-set of markers comprised 2,508.4 $\mathrm{Mb}$ of the genome, with a mean distance between markers of $4.90 \pm 2.89 \mathrm{~kb}$. The SNPs were uniformly distributed across all autosomes since the marker density was similar for all chromosomes, ranging from 4.9 to $5.2 \mathrm{~kb}$ (Table 1). The autosomes differed in size, with BTA25 being the shortest chromosome $(42.8 \mathrm{Mb})$ and BTA1 the longest $(158.5 \mathrm{Mb})$.

After filtering of the SNP data, MAF $<0.20$ were observed in a considerable proportion of SNPs (Figure 1). Similar results have been reported by [6] and [14] for Zebu breeds. However, the mean MAF obtained in the present study (0.25) was slightly higher than that reported by [15] for Nellore cattle (0.19) and by the Bovine Hapmap Consortium using the Illumina Bovine SNP50K BeadChip for Nellore cattle (0.20) [16]. According to [17], the threshold for MAF affects the distribution and extent of LD. Chromosomes BTA2, BTA4, BTA7, BTA15, BTA17, BTA25 and
BTA26 presented a higher proportion of minor alleles (MAF < 0.10), whereas chromosomes BTA6, BTA8, BTA16, BTA22 and BTA23 presented a lower proportion of minor alleles $(\mathrm{MAF}<0.10)$.

All possible SNP pairs on the same chromosome separated by $\leq 100 \mathrm{~kb}$ produced 9,254,142 combinations of SNP pairs to estimate LD across the 29 autosomes. The overall mean LD between marker pairs measured by $\mathrm{r}^{2}$ and $\left|\mathrm{D}^{\prime}\right|$ was 0.17 and 0.52, respectively. Silva et al., 2010 [14] genotyped 25 Gyr sires using a panel of 54,000 markers (SNPs) and obtained a mean LD between adjacent markers measured by $\mathrm{r}^{2}$ and $\left|\mathrm{D}^{\prime}\right|$ of 0.21 and 0.68 , respectively. The present results and those reported in previous studies confirm that the $\left|\mathrm{D}^{\prime}\right|$ parameter overestimates LD, especially in cases of low MAF.

The mean LD between adjacent SNPs across autosomes ranged from 0.003 to 0.21 for $\mathrm{r}^{2}$ and from 0.12 to 0.59 for $\left|\mathrm{D}^{\prime}\right|$ (Table 1). Silva et al., 2010 [14] reported slightly higher values for Gyr cattle, ranging from 0.17 to 0.24 for $\mathrm{r}^{2}$ and from 0.60 to 0.72 for $\left|\mathrm{D}^{\prime}\right|$, respectively. Lower levels of LD $\left(r^{2}<0.16\right)$ were estimated for chromosomes BTA1, BTA27, BTA28 and BTA29. This relatively low level of LD obtained for these chromosomes is in contrast to findings previously published for Zebu

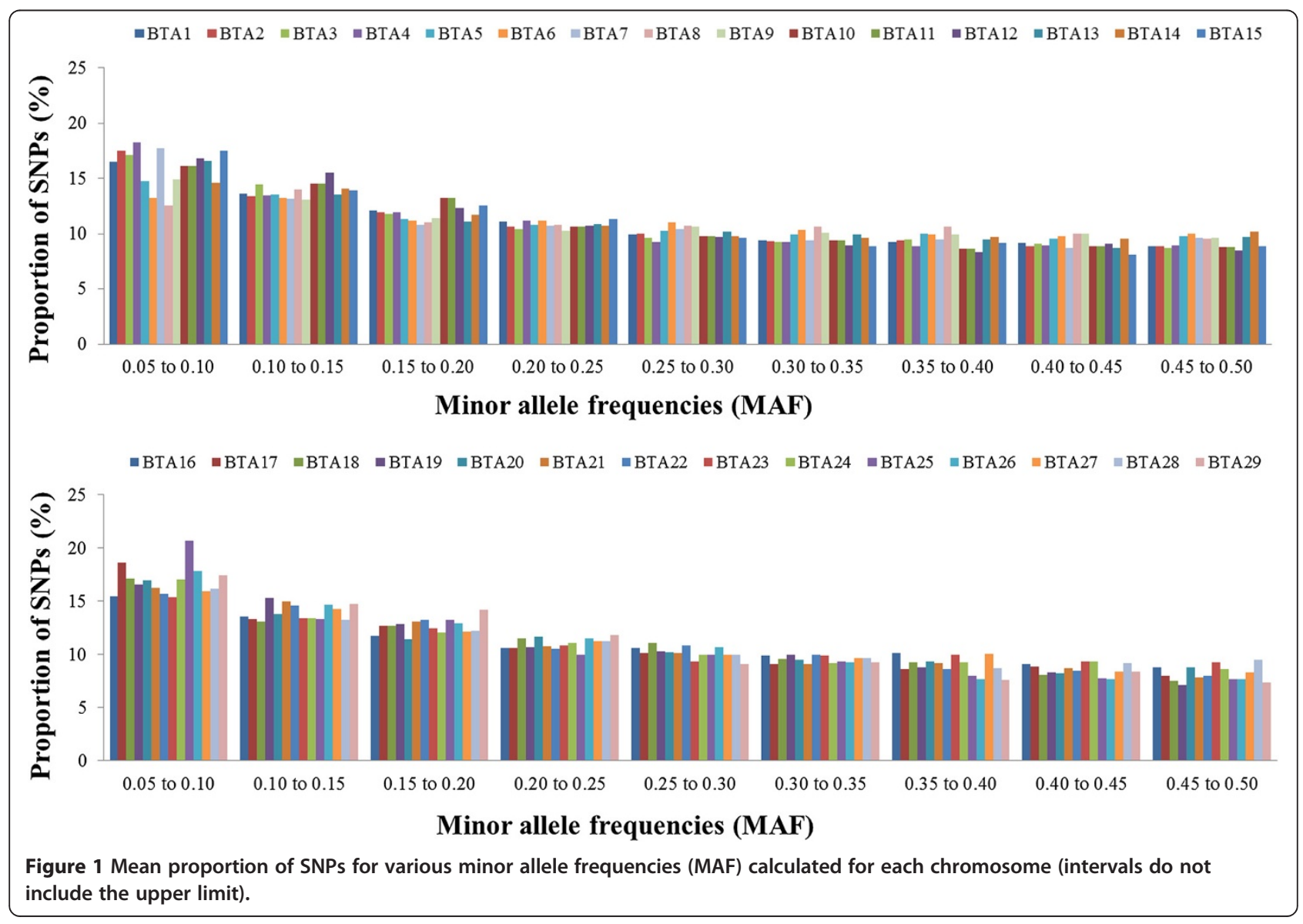


breeds [6,14]. According to [18], there is a wide variation in autosomal recombination rates, a fact, among others, that leads to marked diversity in the pattern of LD in different genomic regions. However, the results obtained in this study for BTA1, BTA27, BTA28 and BTA29 can probably be attributed to a sampling variation since the number of markers, marker density, mean MAF or proportion of MAF did not differ from the other autosomes studied.

To analyze the decline in LD according to physical distance between markers, synthetic SNP pairs were classified into intervals (bins) based on the distance between markers and mean values of $r^{2}$ and $\left|D^{\prime}\right|$ were estimated for each bin per autosome (Figures 2 and 3) and for the whole genome (Table 2). The LD decreased with increasing physical distance between markers (Table 2). In contrast to this clear decrease of LD measured by $\mathrm{r}^{2}$, the changes in $\left|\mathrm{D}^{\prime}\right|$ indicated a less pronounced decline of LD (Figures 2 and 3). Moderate levels of $r^{2}(0.20$ to 0.34$)$ were observed at distances $<30 \mathrm{~kb}$. When the distance between markers increased from 30 to $100 \mathrm{~kb}$, the mean $\mathrm{r}^{2}$ value decreased from 0.20 to 0.11 . A high variability in $\mathrm{r}^{2}$ estimates was observed for marker distances of more than $10 \mathrm{~kb}$. Markers showing LD $\left(\mathrm{r}^{2}\right)$ higher than 0.30 and 0.15 had an average spacing of 38.9 and $41.8 \mathrm{~kb}$, respectively. However, not all markers with a spacing of 40 to $50 \mathrm{~kb}$ presented an $\mathrm{r}^{2}$ value higher than 0.3. For distances of less than $40 \mathrm{~kb}$, the proportion of markers with an $r^{2}>0.15$ and $>0.30$ ranged from 35 to $57 \%$ and from 21 to $42 \%$, respectively. This proportion was lower than that reported by [19] (68.34\%) for markers spacing from 0 to $0.1 \mathrm{Mb}$, who genotyped 821 sires using 5,564 SNPs and the same threshold (0.30) for LD $\left(\mathrm{r}^{2}\right)$. Recently, [20] genotyped 810 Holstein cattle using the Illumina Bovine SNP50K panel and found that, for SNPs separated by less than $100 \mathrm{~kb}$, the proportion of those in LD $\left(r^{2}\right)>0.25$ was $29 \%$.

Except for autosomes BTA1, BTA27, BTA28 and BTA29, the level of $L D\left(r^{2}\right)$ was higher than 0.20 for markers separated by less than $20 \mathrm{~kb}$, and higher than 0.30 for markers separated by less than $3 \mathrm{~kb}$. For marker distances higher than $100 \mathrm{~kb}$, the level of $\mathrm{LD}\left(\mathrm{r}^{2}\right)$ decreased from $0.11(100$

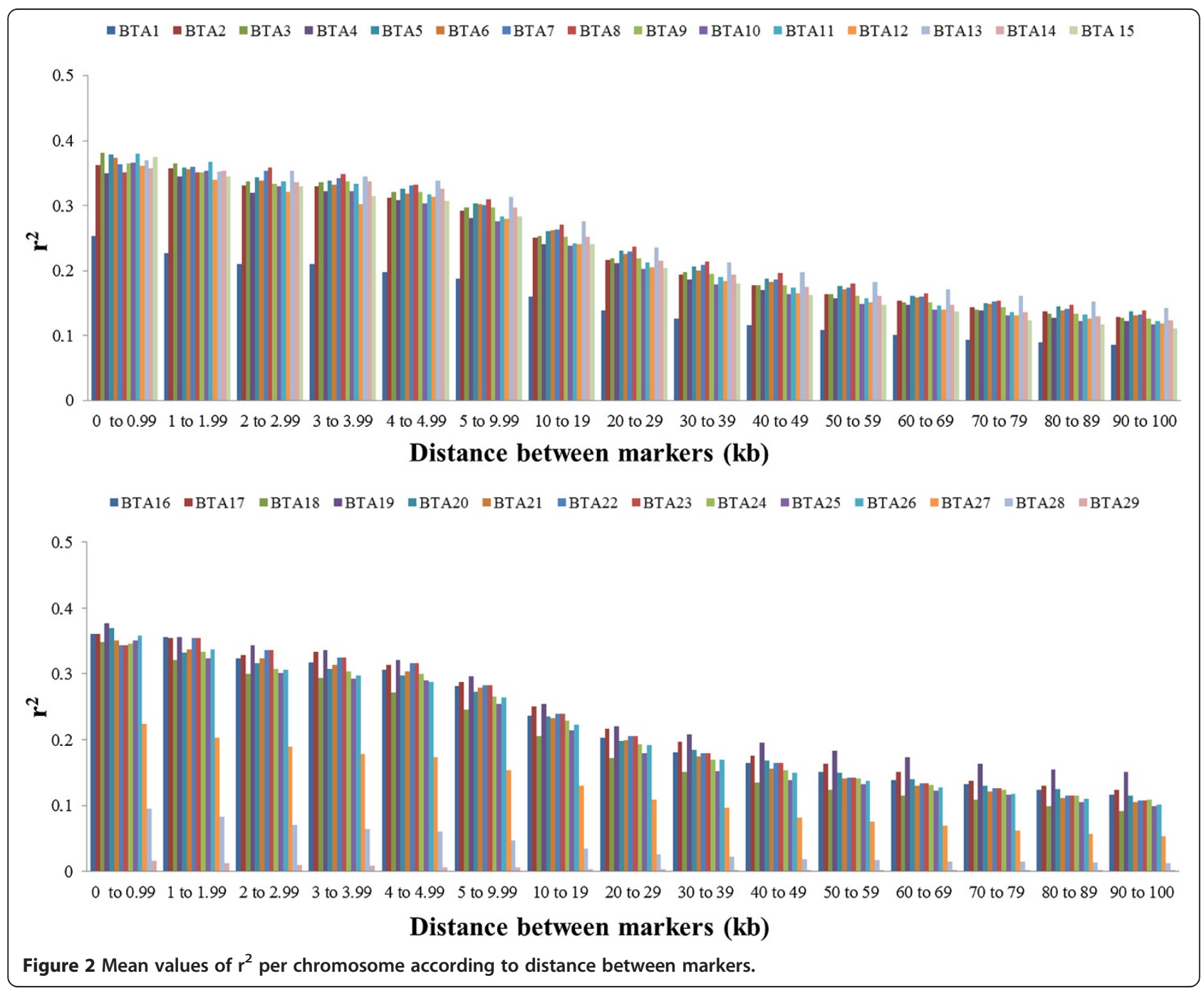




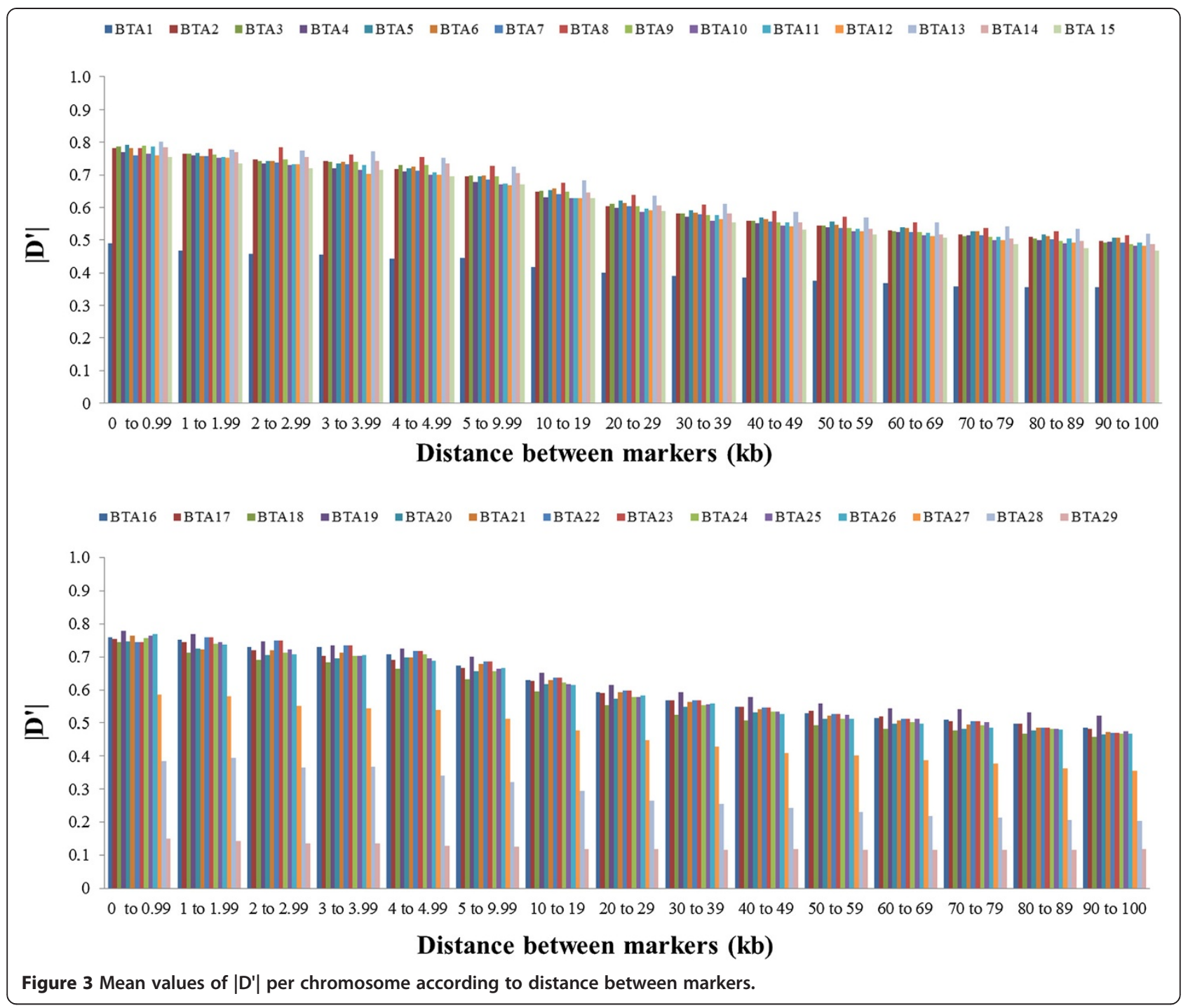

$\mathrm{kb})$ to $0.05(1,000 \mathrm{~kb})$ (data not shown). McKay et al., 2007 [6] estimated the LD between all marker pairs (synthetic markers) in eight cattle breeds (Bos taurus and Bos indicus) and reported a mean $\mathrm{LD}\left(\mathrm{r}^{2}\right)$ ranging from 0.15 to 0.20 for a physical distance of $100 \mathrm{~kb}$ between adjacent markers.

In the present study, certain autosomes presented higher LD than others. In addition, when autosomes with low levels of LD $\left(r^{2}<0.17\right)$ were excluded (BTA1, BTA27, BTA28 and BTA29), a linear relationship was observed between chromosome length and LD $\left(r^{2}\right)$, i.e., the level of LD increased with increasing chromosome size. According to [18], recombination rates decrease as the length of the chromosome increases. In a recent study, [10] found no association between chromosome size and level of LD. However, these authors used a Bos taurus cattle population and a much lower marker density.

The use of SNP pairs with low allele frequencies tends to underestimate LD. Polymorphisms with high allele frequencies are thus preferred for a less biased estimation of LD [21]. We therefore analyzed the effect of MAF on the estimates of $\left|D^{\prime}\right|$ and $r^{2}$ (Figures 4 and 5). The LD $\left(\mathrm{r}^{2}\right)$ between markers was higher when the MAF threshold was high (0.15), particularly when the distance between markers was short (Figure 4). Yan et al., 2009 [22], genotyping 632 maize lines using 1,229 SNP markers, showed that the LD $\left(\mathrm{r}^{2}\right)$ between markers increased with increasing MAF threshold, especially in the case of very close SNP pairs $(0-10 \mathrm{~kb})$. For adjacent markers $(<10 \mathrm{~kb})$, the $\left|D^{\prime}\right|$ remained unchanged for different MAF thresholds (Figure 5). For more distant markers, the $\left|\mathrm{D}^{\prime}\right|$ was lower as the MAF threshold increased. According to [10], the LD measured by $\left|D^{\prime}\right|$ is underestimated as the MAF threshold increases (above 0.25). When LD is determined by $\left|\mathrm{D}^{\prime}\right|$, the denominator in the formula is the product between allele frequencies. Thus, in the case of SNP pairs with low allele frequencies, D' will be divided by a small number, resulting 
Table 2 Linkage disequilibrium $\left(r^{2}\right.$ and $\left.\left|D^{\prime}\right|\right)$ between pairs (N) of synthetic SNPs separated by different distances across all autosomes

\begin{tabular}{|c|c|c|c|c|c|c|c|c|}
\hline Distance (kb) & $\mathrm{N}$ & Mean $r^{2} \pm S D$ & Median $r^{2}$ & Mean $\left|D^{\prime}\right| \pm S D$ & Median |D'| & $\% r^{2}>0.3^{1}$ & $\% r^{2}>0.15^{1}$ & $\%\left|D^{\prime}\right|>0.8$ \\
\hline $0-1$ & 54404 & $0.34 \pm 0.33$ & 0.21 & $0.72 \pm 0.32$ & 0.90 & 42 & 57 & 44 \\
\hline $1-2$ & 99488 & $0.32 \pm 0.33$ & 0.19 & $0.70 \pm 0.33$ & 0.88 & 40 & 55 & 42 \\
\hline $2-3$ & 104465 & $0.31 \pm 0.32$ & 0.18 & $0.69 \pm 0.33$ & 0.86 & 38 & 54 & 41 \\
\hline $3-4$ & 112729 & $0.30 \pm 0.32$ & 0.17 & $0.68 \pm 0.33$ & 0.84 & 38 & 53 & 40 \\
\hline $4-5$ & 108799 & $0.29 \pm 0.31$ & 0.16 & $0.67 \pm 0.33$ & 0.82 & 36 & 51 & 39 \\
\hline $5-10$ & 514160 & $0.27 \pm 0.30$ & 0.14 & $0.64 \pm 033$ & 0.77 & 33 & 48 & 37 \\
\hline $10-20$ & 977946 & $0.23 \pm 0.28$ & 0.10 & $0.60 \pm 0.33$ & 0.68 & 28 & 43 & 34 \\
\hline $20-30$ & 946535 & $0.20 \pm 0.26$ & 0.08 & $0.57 \pm 0.33$ & 0.61 & 24 & 38 & 30 \\
\hline $30-40$ & 927788 & $0.18 \pm 0.24$ & 0.07 & $0.54 \pm 0.33$ & 0.57 & 21 & 35 & 28 \\
\hline $40-50$ & 918536 & $0.16 \pm 0.23$ & 0.06 & $0.52 \pm 0.33$ & 0.53 & 19 & 32 & 26 \\
\hline $50-60$ & 908630 & $0.15 \pm 0.22$ & 0.05 & $0.51 \pm 0.32$ & 0.50 & 17 & 29 & 24 \\
\hline $60-70$ & 901928 & $0.14 \pm 0.21$ & 0.05 & $0.50 \pm 0.32$ & 0.48 & 15 & 28 & 23 \\
\hline $70-80$ & 895944 & $0.13 \pm 0.20$ & 0.04 & $0.48 \pm 0.32$ & 0.47 & 14 & 26 & 21 \\
\hline $80-90$ & 893132 & $0.12 \pm 0.19$ & 0.04 & $0.47 \pm 0.31$ & 0.45 & 13 & 24 & 20 \\
\hline $90-100$ & 889644 & $0.11 \pm 0.18$ & 0.04 & $0.47 \pm 0.31$ & 0.44 & 12 & 23 & 19 \\
\hline
\end{tabular}

SNP: single-nucleotide polymorphism; SD: Standard deviation. ${ }^{1}$ Percentage of SNP pairs with $r^{2}>0.3, r^{2}>0.15$ and $\left|D^{\prime}\right|>0.8$.

in a large value for $\left|D^{\prime}\right|[21]$. The results of the present study indicate a considerable variation in the magnitude and pattern of LD in the Nellore genome. As a consequence, two markers that are very close may show a low level of LD, whereas more distant markers may show a higher level of LD than expected. This variation is probably due to different recombination rates between and within chromosomes, heterozygosity, genetic drift, and effects of selection [21].

The level of LD between adjacent markers (distance of less than $30-40 \mathrm{~kb}$ ) observed in the present study was lower than that reported in other studies on Bos taurus cattle and similar to that found in studies using Bos indicus. The differences between taurine and indicine breeds decrease for markers separated by 80 to $100 \mathrm{~kb}$. However, it is generally difficult to compare the level of LD obtained in different studies because of differences in sample size, measures of LD, type of markers and marker density, as well as because of the recent history of the population [11]. Nevertheless, differences between indicine and taurine cattle that occurred during the historical process of domestication and selection and as a consequence of the effective size of populations seem to explain the discrepancy in LD at short distances between markers [23]. Another reason is the fact that Bos indicus populations

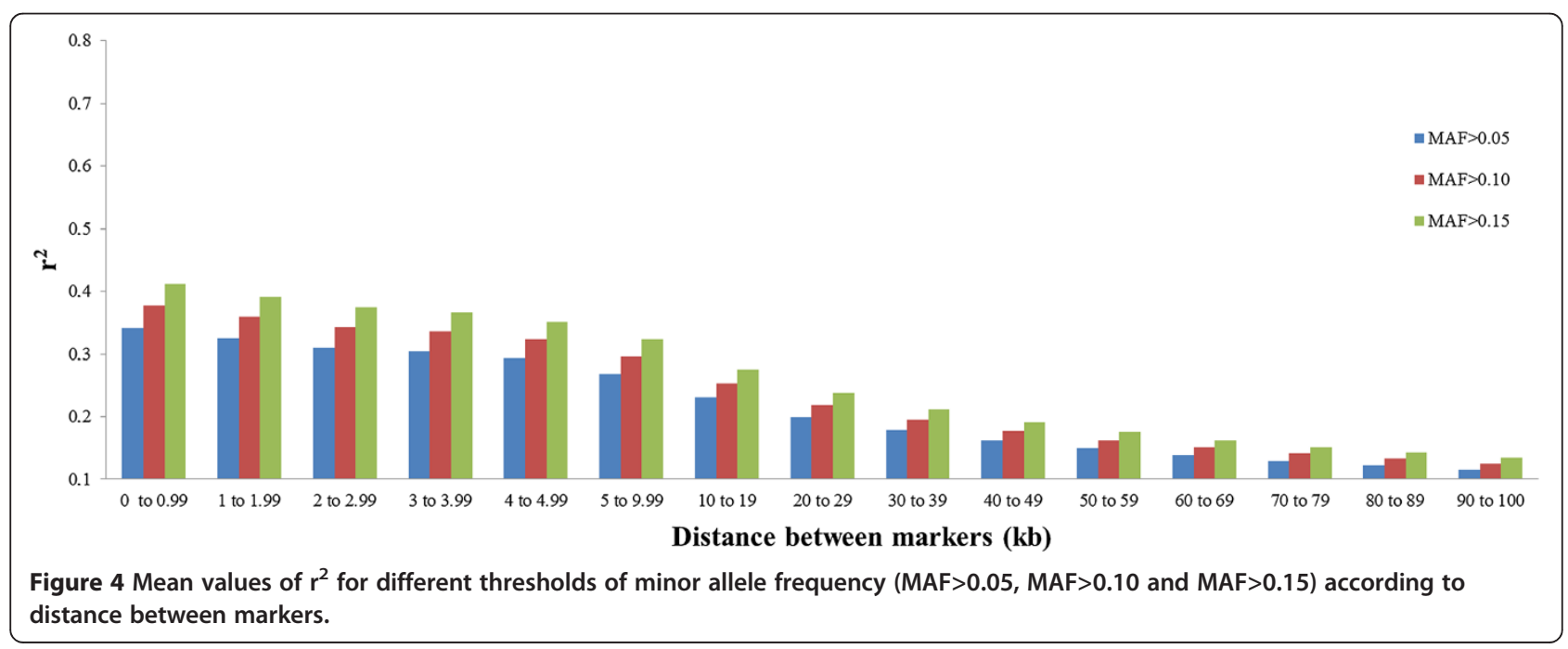




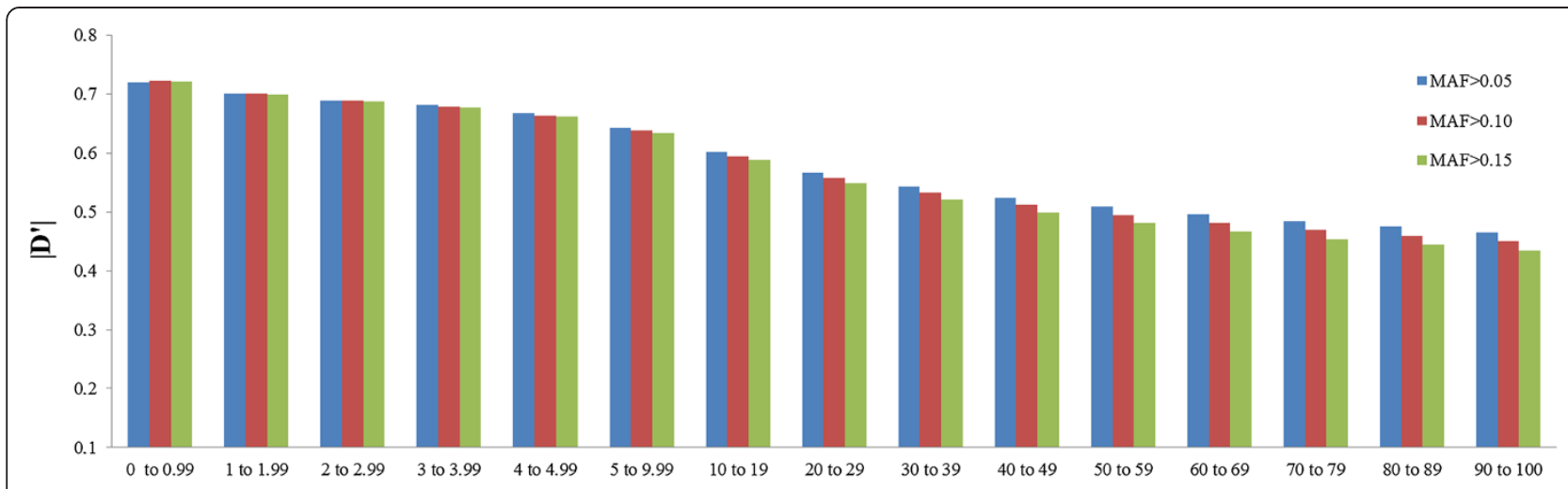

Distance between markers (kb)

Figure 5 Mean values of $\left|D^{\prime}\right|$ for different thresholds of minor allele frequency (MAF $>0.05, M A F>0.10$ and MAF $>0.15$ ) according to distance between markers.

present a higher proportion of low-frequency alleles in the HD SNP chip than Bos taurus populations which, in turn, influences LD estimates [6,24].

\section{Conclusions}

The level of LD estimated for markers separated by less than $30 \mathrm{~kb}$ indicates that the High Density Bovine SNP BeadChip will likely be a suitable tool for prediction of genomic breeding values in Nellore cattle. Further studies investigating the magnitude of LD in a larger sample of animals from this population are needed to confirm the estimates obtained here.

\section{Methods}

Seven hundred and ninety five Nellore bulls born in 2008 and 2009 from 117 sires, which belonged to the three Brazilian beef cattle breeding programs, were used in the present study. This research did not involve humans and the Animal Care and Use Committee approval was not obtained for this study because the data were from an existing database. Genotyping was performed by high density bead array technology using the Illumina Infinium HD Assay ${ }^{\circledR}$ and Illumina HiScan system $^{\circledR}$. The High Density Bovine SNP BeadChip contains 777,962 SNP markers spread across the genome at a mean distance of $3.43 \mathrm{~kb}$ between markers. The HiScan images and genotypes were first analyzed using the Genome Studio ${ }^{\circledR}$ software (Illumina). A total of 1,465 markers were excluded due to unknown genome position and 15,116 markers were monomorphic. For sake of the present study, only autosomal markers with minor allele frequencies (MAF) higher than $0.05,0.10$ or 0.15 were included in the LD analysis. In addition, only markers with a call rate $>0.90$ and heterozygote excess $<0.30$ were considered. A total of 11,785 markers were excluded because they showed low mean cluster intensity (AB_R, AA_R or BB_R: mean < 0.3).

For DNA extraction, about $5 \mathrm{~g}$ of longissimus dorsi muscle sample was removed and stored in a $2 \mathrm{ml}$ Eppendorf tube. The tubes were identified with the identification of each animal and then stored in styrofoam boxes in a freezer at $-20^{\circ} \mathrm{C}$. Next, 25 to $30 \mathrm{mg}$ of muscle tissue specimens were weighed on an aluminum sheet using an analytical balance and transferred to Eppendorf tubes (1.5 to $2 \mathrm{ml}$ ). DNA was extracted from the muscle samples using the DNeasy Blood \& Tissue Kit (Qiagen $\mathrm{GmbH}$, Hilden, Germany) according to the manufacturer's instructions.

The LD between two SNPs was evaluated using $\mathrm{r}^{2}$ and the absolute value of $\mathrm{D}^{\prime}$. The $\mathrm{r}^{2}$ was calculated as follows:

$$
\begin{aligned}
r^{2} & =\frac{\left(\text { freq. } A B^{*} \text { freq.ab-freq. } A b^{*} \text { freq. } a B\right)^{2}}{\left(\text { freq. } A^{*} \text { freq. } a^{*} \text { freq. } B^{*} \text { freq. } b\right)} \\
& =\frac{(D)^{2}}{\left(\text { freq. } A^{*} \text { freq. } a^{*} \text { freq. } B^{*} \text { freq. } b\right)}
\end{aligned}
$$

where,

$$
D=\text { freq. } A B-\text { freq. } A^{*} \text { freq. } B
$$

and

$$
D^{\prime}=\left\{\begin{array}{ll}
\left.\frac{D}{\min \left(\text { freq. } A^{*} \text { freq. } b, \text { freq. } \cdot a^{*} \text { freq. } B\right)}\right) & \text { if } D>0 \\
\frac{D}{\min \left(\text { freq. } A^{*} \text { freq. } B, \text { freq. } . a^{*} \text { freq. } b\right)} & \text { if } D<0
\end{array}\right\}
$$

where freq. $A$, freq. $a$, freq. $B$ and freq. $b$ are the frequencies of alleles $\mathrm{A}, \mathrm{a}, \mathrm{B}$ and $\mathrm{b}$, respectively, and freq. $A B$, freq. $a b$, freq. $a B$ and freq. $A b$ are the frequencies of haplotypes $A B, a b, a B$ and $A b$ in the population, respectively. 
If the two loci are independent, the expected frequency of haplotype $\mathrm{AB}$ (freq. $A B$ ) is calculated as the product between freq. $A$ and freq. $B$. A freq. $A B$ higher or lower than the expected value indicates that these two loci in particular tend to segregate together and are in LD. The measures of $\operatorname{LD}\left(\mathrm{r}^{2}\right.$ and $\left.\left|\mathrm{D}^{\prime}\right|\right)$ were calculated for all marker pairs of each chromosome using the SnppldHD software (Sargolzaei, M., University of Guelph, Canada).

Only maternal haplotypes were considered for the estimation of LD measures $\left(r^{2}\right.$ and $\left.\left|D^{\prime}\right|\right)$. The exclusive use of maternal haplotypes is a common practice in studies estimating LD when the population consists of half-sib families, as was the case here. The reason is that the pedigree structure leads to the over-representation of paternal haplotypes in the sample since sires have multiple progenies in the dataset, which might increase the frequency of certain haplotypes and consequently overestimate LD [21].

\section{Abbreviations}

LD: Linkage disequilibrium; SNP: Single nucleotide polymorphism; MAF: Minor allele frequency; QTL: Quantitative trait loci.

\section{Competing interests}

The authors declare that they have no competing interests.

\section{Authors' contributions}

RE and FB participated in the design of the study, performed the genome studio analysis, statistical analysis and drafted the manuscript, $A A B$ participated in the design of the study, helped with the genome studio analysis, statistical analysis and to draft the manuscript, FRPS and DFC participated in the DNA extraction, carried out the molecular analysis and helped to draft the manuscript, DMG, RLT and RE participated in the collection and preparation of the samples, HNO participated in the design of the study and to draft the manuscript, HT helped to draft the manuscript, MS participated in the design of the study, helped with LD analysis and to draft the manuscript, FSS participated in the design of the study, helped with $L D$ analysis and to draft the manuscript, RC participated in the design of the study, helped the genome studio analysis, statistical analysis and to draft the manuscript, JAF carried out the molecular analysis and helped to draft the manuscript, LGA conceived the study and participated in its design and coordination and helped to draft the manuscript. All authors read and approved the final manuscript.

\section{Acknowledgements}

This work was supported by Fundação de Amparo à Pesquisa do Estado de São Paulo. We are indebted to the Conexão Delta $G^{\circledR}$, Paint - CRV Lagoa and Nelore Qualitas for providing the cattle tissue samples.

\section{Author details}

${ }^{1}$ Faculdade de Ciências Agrárias e Veterinárias, UNESP, Jaboticabal, SP 14884-000, Brazil. ${ }^{2}$ Instituto Nacional de Ciência e Tecnologia - Ciência Animal (INCT- CA), Viçosa, MG 36570 000, Brazil. ${ }^{3}$ Departamento de Nutrição e Produção Animal, Faculdade de Medicina Veterinária e Zootecnia, USP, Pirassununga, SP, Brazil. ${ }^{4}$ Centre for Genetic Improvement of Livestock, Department of Animal and Poultry Science, University of Guelph, Guelph, ON, Canada. ${ }^{5} \mathrm{CNPq}$ Fellowship, National Council of Technological and Scientific Development, 71605-001, SHIS QI 1,Conjunto B, Brasília, DF, Brazil. ${ }^{6}$ GenSys Consultores Associados, Porto Alegre, Brazil.

Received: 5 December 2012 Accepted: 25 April 2013 Published: 5 May 2013

\section{References}

1. Albuquerque $L G$, Mercadante MEZ, Pereira EJ: Recent studies on the genetic basis for selection of Bos indicus for beef production. In Proceedings of the 8th World Congress on Genetics Applied to Livestock Production: 13-18 August 2006. Belo Horizonte, Brazil.

2. ANUALPEC: Anuário da Pecuária Brasileira. São Paulo: Instituto FNP; 2011.

3. Yokoo MJl, Albuquerque LG, Lôbo RB, Sainz RD, Carneiro JML Jr, Bezerra AF, Araujo FRC: Estimation of genetic parameters for hip height, weight and scrotal circumference in Nelore cattle. Rev. Bras. Zootecn 2007, 36:1761-1768.

4. Bennewitz J, Solberg T, Meuwissen T: Genomic breeding value estimation using nonparametric additive regression models. Genet Sel Evol 2009, 41:20.

5. Calus MPL, Roos SPW, Veerkamp RF: Estimating genomic breeding values from the QTL-MAS workshop data using a single SNP and haplotype/IBD approach. BMC Proc 2009, 3:S01-S10

6. McKay SD, Schnabel RD, Murdoch BM, Matukumalli LK, Aerts J, Wouter Coppieters W, Crews D, Dias Neto E, Gill CA, Gao C, Mannen H, Stothard P, Wang Z, Van Tassell CP, Williams JL, Taylor JF, Stephen S, Moore SS: Whole genome linkage disequilibrium maps in cattle. BMC Genet 2007, 8:74.

7. Hill WG, Robertson A: Linkage disequilibrium in finite populations. Theor Appl Genet 1968, 38:226-231.

8. Hill WG: Estimation of effective population size from data on linkage disequilibrium. Genet Res 1981, 38:209-216.

9. Valdar W, Solberg LC, Gauguier D, Burnett S, Klenerman P, Cookson WO, Taylor MS, Rawlins JN, Mott R, Flint J: Genome-wide genetic association of complex traits in heterogeneous stock mice. Nat Genet 2006, 38:879-887.

10. Bohmanova J, Sargolzaei M, Schenkel F: Characteristics of linkage disequilibrium in North American Holsteins. BMC Genomics 2010, 11:421.

11. Pritchard JK, Przeworski M: Linkage disequilibrium in humans: models and data. Am J Hum Genet 2001, 69:1-14.

12. Marques E, Schnabel R, Stothard P, Kolbehdari D, Wang Z, Taylor JF, Moore SS: High density linkage disequilibrium maps of chromosome 14 in Holstein and Angus cattle. BMC Genet 2008, 9:45.

13. Villa-Angulo R, Matukumalli LK, Gill CA, Choi J, Van Tassell CP, John J, Grefenstette J: High-resolution haplotype block structure in the cattle genome. BMC Genet 2009, 10:19.

14. Silva CR, Neves HHR, Queiroz SA, Sena JAD, Pimentel ECG: Extent of linkage disequilibrium in Brazilian Gyr dairy cattle based on genotypes of Al sires for dense SNP markers. In Proceedings of the 9th World Congress on Genetics Applied to Livestock Production: 01-06 August 2010. Leipzig, Germany.

15. Matukumalli LK, Lawley CT, Schnabel RD, Taylor JF, Allan MF, Heaton MP, O'Connell J, Moore SS, Smith TP, Sonstegard TS, Van Tassell CP: Development and characterization of a high density SNP genotyping assay for cattle. PLoS One 2009, 4:e5350

16. Gibbs RA, Taylor JF, Van Tassell CP, Barendse W, Eversole KA, Gill CA, Green RD, Hamernik DL, Kappes SM, Lien S: Genome-wide survey of SNP variation uncovers the genetic structure of cattle breeds. Science 2009, 324:528-532.

17. Khatkar MS, Nicholas FW, Collins AR, Zenger KR, Cavanagh JA, Barris W, Schnabel RD, Taylor JF, Raadsma HW: Extent of genome-wide linkage disequilibrium in Australian Holstein-Friesian cattle based on a high density SNP panel. BMC Genomics 2008, 9:187.

18. Arias JA, Keehan M, Fisher P, Coppieters W, Spelman R: A high density linkage map of the bovine genome. BMC Genet 2009, 10:18.

19. Sargolzaei $M$, Schenkel $F S$, Jansen $G B$, Schaeffer LR: Extent of linkage disequilibrium in Holstein cattle in North America. J Dairy Sci 2008, 91:2106-2117.

20. Qanbari S, Pimentel ECG, Tetens J, Thaller G, Lichtner P, Sharifi AR, Simianer $H$ : The pattern of linkage disequilibrium in German Holstein cattle. Anim Genet 2010, 41:346-356.

21. Reich DE, Lander ES: On the allelic spectrum of human disease. Trends Genet 2001, 17:502-10.

22. Yan J, Shah T, Warburton ML, Buckler ES, McMullen MD, Crouch J: Genetic characterization and linkage disequilibrium estimation of a global maize collection using SNP markers. PLoS One 2009, 4:e8451.

23. Tenesa A, Navarro P, Hayes BJ, Duffy DL, Clarke GM, Goddard ME, Visscher PM: Recent human effective population size estimated from linkage disequilibrium. Genome Res 2007, 17:520-526.

24. Weiss KM, Clark AG: Linkage disequilibrium and the mapping of complex human traits. Trends Genet 2002, 18:19-24.

doi:10.1186/1471-2164-14-305

Cite this article as: Espigolan et al:: Study of whole genome linkage disequilibrium in Nellore cattle. BMC Genomics 2013 14:305. 